\title{
The Computer Aided Fault Tree Modeling and Analysis of the Refrigerator Evaporator Failure
}

\author{
Quanyu Yu*, Jie Liu and Kangkang Zhang
}

School of Mechanical \& Automotive Engineering, Anhui Polytechnic University, Wuhu, 241000, Anhui, China

\begin{abstract}
The paper analyzes the various factors that cause failure of refrigerator evaporator. The refrigerator evaporator failure spectrum is constructed through qualitative analysis of the fault tree system after building a corresponding fault tree system. There is an analysis procedure of fault tree system based on computer aided fault tree analysis system (CAFTA).
\end{abstract}

Keywords: Computer aided modeling, fault tree analysis, refrigerator, reliability,

\section{INTRODUCTION}

The refrigerator is an equipment that constantly maintain temperature. The refrigeration system is the core system of refrigerator. Compressor compressed the refrigerant into high pressure saturated gas (ammonia or Freon). This gaseous refrigerant passes through the condenser to condensate and through the throttle into the evaporator after throttling device. There is a cold output equipment in refrigeration that is mainly the role of "heat". For example, the evaporator is connected to each room in the building at first; second, serpentine evaporator tube exchanger with air, the air conditioning blowing in the air of the room through a blast at last. Evaporator hunting refrigerant heat exchanger tube into a low pressure steam back to the compressor after it is being compressed by the compressor. So recycling is a complete refrigeration system. It is so important that heat exchanges components from evaporator of refrigeration system. May be it will lead to failure of refrigerating system of refrigerator when the failure of evaporator occurs.

Analyzing the failure of refrigerator evaporator is mainly judged by experience and test method in real life. This method require the work experience of staff so high that fasten efficiency but the accuracy is not high. There will be some mistakes when making a judge because of the inability to find the fundamental source of failure.

Obviously, the failure analysis of refrigerator evaporator is very important. Fault tree analysis (FTA) is one of the main methods of failure analysis. In this paper, through the analysis of various factors which may cause the failure of the evaporator, the fault tree logic diagram and evaporator failure spectrum are drawn, the evaporator failure analysis of all the possible combinations and probabilities is determined.

*Address correspondence to this author at the School of Mechanical \& Automotive Engineering, Anhui Polytechnic University, Wuhu, 241000, Anhui, China; Tel: 0086-553-2871173; Fax: 0086-553-2871252;

E-mail: yuquanyu@126.com
It is an important reference that enhances the reliability of the refrigeration system of refrigerator.

\section{FAULT TREE ANALYSIS (FTA)}

Fault tree is a graphic and logic representation which leads to combined top possible events of system (fault and normal) model. Fault events are reffered when the system state is not normal. A normal event means it can be expected events. Event is a dynamic change in a system of state. Element of the system includes hardware and software, human and environmental factors. Fault tree analysis (FTA) is a deductive method, Probability is used to determine the potential causes of failure and estimate the fault. Fault tree analysis emphasizes the system design issues and potential failure. Using the deductive tracking system fault and using graphics to describe the system function and behavior. Analysis of reliability provides qualitative and quantitative. Fault tree will set realistic events, especially the failure of most primary. This is the result of the top event system. Fault tree analysis method is a method of analysis of system failure. Refrigerator evaporator failure is to construct fault tree structure.

\section{CONSTRUCT FAULT TREE STRUCTURE OF REFRIGERATOR EVAPORATOR FAILURE}

The paper use evaporator failure as the top event of fault tree in the refrigerator refrigeration system (as shown in Fig. 1) and extend fault tree.

The evaporator as one of the core components of the refrigeration system of refrigerator in the work, it undergoes the effects of time, temperature, voltage, environmental factors. These factors involve the design, material selection, manufacturing process, installation, service etc. These can also be traced back to the primitive. The failure mechanism is known, so there is no need to pursue the reason (that is the bottom event) which represent the event with the appropriate symbol, the logic gate symbols appropriate to the top, middle and bottom events their events are connected to a tree 
diagram. We will obtain the fault tree of refrigerator evaporator failure [1] (as shown in Fig. 2).

\section{QUALITATIVE ANALYSIS OF FAULT TREE TO THE REFRIGERATOR REFRIGERATION SYSTEM}

Fault tree analysis is aimed to find out all the possible causes of system failure or to specify all the possible causes of the top event [2]. To qualitatively identify the weak links of the system is the third aim. In order to achieve this goal, first, the fault tree minimal cut sets and minimal path should be setted. The minimum cut set of the fault tree is the collection of bottom events of the fault tree. When all the basic events in a collection occur, the top event will occur. This collection is called to cut sets for fault tree, if you remove any of these basic events. Set the remaining events will no longer be cut sets of the fault tree is called a minimal cut set. The minimum cut set is the full combination of initial events leading to the top event of the (intersection) [3]. This combination is a minimum combination. In this combination, all failures should lead to the occurrence of the top event. If the cut sets of top event have a failure and do not occur, then the top event will not occur [4].

A systematic approach can be used to analyse fault tree which is according to the nature of the fault tree structure and logic gate for the minimum cut set. Some methods are known to be ascending and descending method [5]. In this paper, using the descending method fault tree to solve the minimum cut set of refrigeration system. Descending method is lead the top event step input time replacement table in the door events (output). If you encounter the logic"or"gate, the input time of vertical tandem can occupy one line. When all the intermediate time tables are replaced with the bottom event, it will stop to replace and remove duplicate excessive rows of time and unnecessary repetition. Therefore each line is a fault tree cut set [6]. According to the inclusion relation that out of cut sets of excess is all the minimal cut sets. In this paper the fault tree is constructed by $G$ that said intermediate event of fault tree. It will use the Arabia number $1,2,3$ to show bottom event of fault tree [7] (as shown in Table 1).

After all events were replaced into bottom events then they were repeated. Fault tree is mainly composed by logic gate at this time. So the most cut is first order cut set. All the minimal cut sets of faulttrees: $(5,6),(7,8),(1),(2),(3),(4),(9)$, (10),(11),(12),(13),(14),(15),(16),(17),(18),(19),(20). According to spectra order sorting of the minimum cut sets to obtain the fault tree failure of refrigerator refrigeration system: $\{(5,6),(7,8),(1),(2),(3),(4),(9),(10),(11),(12),(13),(14),(15),(1$ $6),(17),(18),(19),(20)\}$.

In (18) the minimum concentration has (16) first-order cut sets and 2 second-order cut set. First cut set only contains one bottom event. As long as the bottom event of failure, will show system failure [8]. Second order section set contains two bottom events. Only when the two bottom events at the same time fail, the system will fail. We must strengthen the reliability of all first-order cut sets of bottom events to enhance the reliability of the refrigerator refrigeration system work [9].

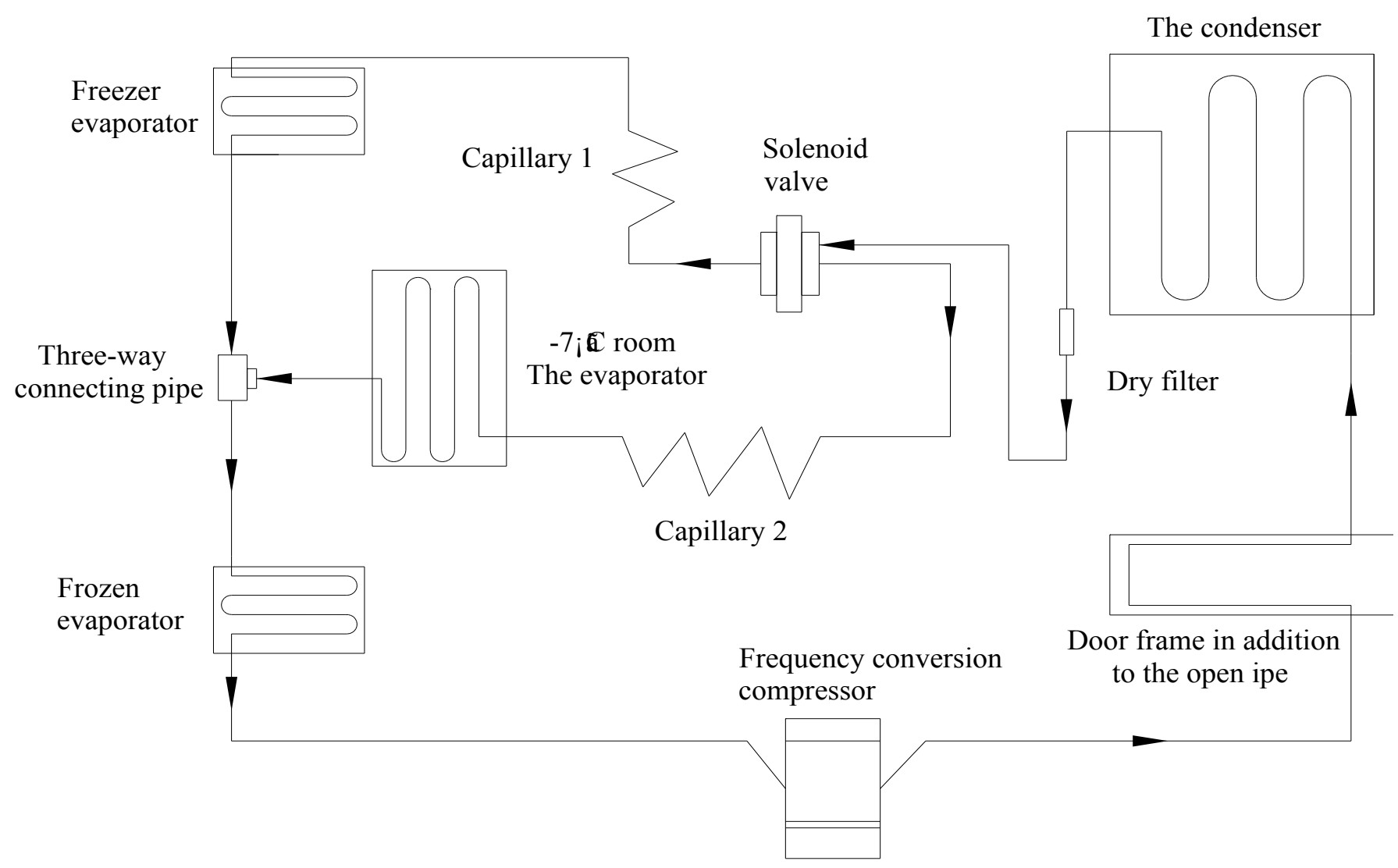

Fig. (1). The refrigeration system of refrigerator. 


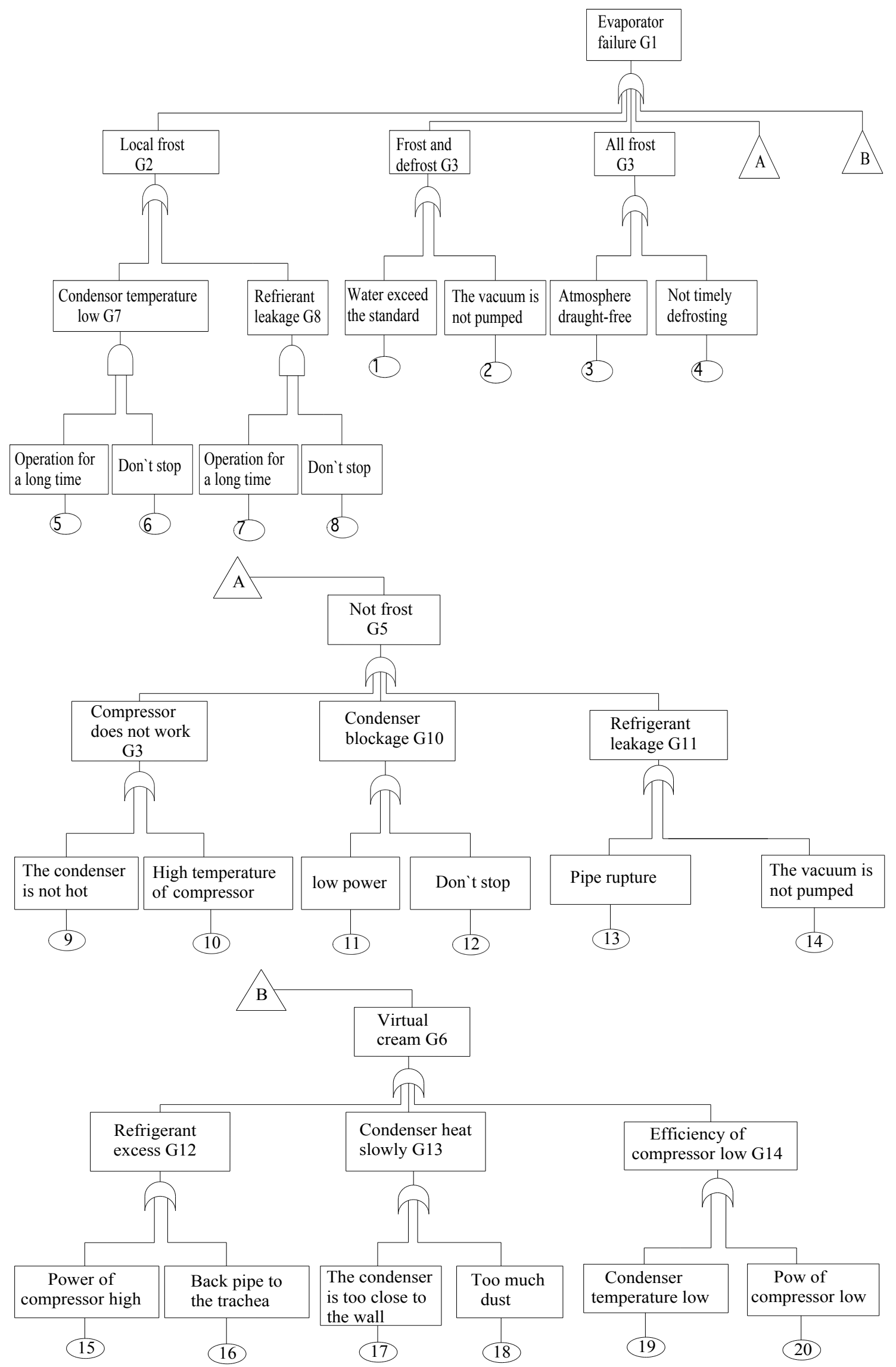

Fig. (2). The fault tree of refrigerator evaporator failure. 
Table 1. The minimum cut sets of fault trees of evaporator.

\begin{tabular}{|c|c|c|c|c|c|c|c|c|}
\hline Step & $\mathbf{1}$ & $\mathbf{2}$ & $\mathbf{3}$ & $\mathbf{4}$ & $\mathbf{5}$ & $\mathbf{6}$ & $\mathbf{7}$ & $\begin{array}{c}\text { The Minimum } \\
\text { Cut Set }\end{array}$ \\
\hline & G1 & G2 & G7 & G7 & G7 & 5,6 & 5,6 & 5,6 \\
\hline & G3 & G8 & G8 & G8 & 7,8 & 7,8 & 7,8 \\
\hline & G4 & G3 & 1 & 1 & 1 & 1 & 1 \\
\hline & G5 & G4 & 2 & 2 & 2 & 2 & 2 \\
\hline & & G5 & 3 & 3 & 3 & 3 & 3 \\
\hline & & & 4 & 4 & 4 & 4 & 4 \\
\hline & & & G5 & G5 & G9 & 9 & 9 \\
\hline & & & G6 & G12 & G10 & 10 & 10 \\
\hline & & & & G13 & G11 & 11 & 11 \\
\hline & & & & G14 & 15 & 12 & 12 \\
\hline & & & & & 16 & 13 & 13 \\
\hline & & & & & 17 & 14 & 14 \\
\hline & & & & & 18 & 15 & 15 \\
\hline & & & & & 19 & 16 & 16 \\
\hline & & & & & 20 & 17 & 17 \\
\hline & & & & & & 18 & 18 \\
\hline & & & & & & 19 & 19 \\
\hline & & & & & & 20 & 20 \\
\hline & & & & & \\
\hline
\end{tabular}

\section{QUANTITATIVE ANALYSIS OF FAULT TREE}

Fault tree quantitative analysis is done by using the fault tree as the calculation model. When bottom event probability condition are known, we can obtain the probability of occurrence top event (i.e., the probability of system failure). Thus, it can assess reliability, safety and risk of system. Quantitative analysis method of fault tree is the inclusionexclusion principle method and the structure function method. Using the Ci representation of the fault tree of the I minimum cut sets and $\mathrm{m}$ indicates the number of minimal cut sets. Fault tree (top) as the top event occurrence probability formula [10]:

$$
\begin{aligned}
& P(\text { тоР })=\sum_{i=1}^{m} P\left\{C_{i}\right\}-\sum_{i=1}^{m-1} \sum_{j=i+1}^{m} P\left\{C_{i} \cap C_{j}\right\}+ \\
& \sum_{i=1}^{m-2} \sum_{j=i+1}^{m-1} \sum_{k=j+1}^{m} P\left\{C_{i} \cap C_{j} \cap C_{k}\right\}-\cdots+\cdots \\
& +(-1)^{m-1} P\left\{C_{1} \cap C_{2} \cap \cdots \cap C_{m}\right\}
\end{aligned}
$$

The structure function is used to solve probability of top event. Structure function that the argument for the system unit state is a Boolean function of the system state [11]. If the fault tree node is logical and gate connection, we set the output event variable i.e. Y and the input event X. Structure function that constructs input event's number is $i$ when it does not occur:
$\Phi(Y)=\prod_{i=1}^{n} X_{i}=X_{1} X_{2} \cdots X_{n}(i=1,2, \cdots n)$

If the fault tree node is connected to the gate, we can design output event variable information the same as input. Structure function is :

$\Phi(Y)=1-\left(1-X_{1}\right)\left(1-X_{2}\right) \cdots\left(1-X_{n}\right)$

It follows that we can analyze the conventional fault tree from the bottom to the top step by step. There must be the structure function of each logic gate node and then iteratively until structure construct the ion of the top event $\Phi(Y)$ [12]. The probability of the top event is:

$P($ TоP $)=E[\Phi(Y)]$

The probability of an event occurring is equal to the expected value of the structure function.

From the methods of the above two kinds of solving probability of the top event, no matter which kind of method is applied the calculation process is very complex for complex fault trees. But there are a lot of procedures for computer aided fault tree. Practical software is CAFTA, that is composed by CAFTA, FDA, Safety. These have the realization of data management, reliability model of fault tree analysis calculation, calculation and analysis of the results and data security management functions. When you using fault tree analysis system CAFTA, we can get the results of qualitative and quantitative analysis of fault tree through reliability simulation analysis module of the CAFTA input failure distribution of every type of bottom events [13].

\section{CONCLUSION}

Use the refrigerator evaporator failure as the top event of fault tree to construct the fault tree. This model can directly reflect the various modes of failure [14]. Using the descending method to get the refrigeration efficiency refrigerator failure fault spectrum $\{(5,6),(7,8),(1),(2),(3),(4),(9),(10)$, (11),(12),(13),(14),(15),(16),(17),(18),(19),(20),(21)\}. One group of numbers represents a failure mode and every minimal cut set is likely to cause failure of refrigerator evaporator. Using fault tree analysis of refrigerator evaporator failure to enhance the reliability of the refrigerator is of great significance. So the failure analysis of bottom events of the fault tree can be difficult. We need a long time to investigate and collect the fault information of refrigerator evaporator failure and reorganize them to obtain the reasonable results.

\section{CONFLICT OF INTEREST}

The authors confirm that this article content has no conflict of interest.

\section{ACKNOWLEDGEMENTS}

Declared done.

\section{REFERENCES}

[1] Y. Quanyu, "Fault tree analysis of reliability of forklift gearbox", Journal of Anhui Mechanical \& Electrical Engineering Institute, vol. 16, pp. 31-34, 2001.

[2] F. Jijun, "The failure forms and analysis of automobile engine crankshaft", Failure analysis and Prevention, pp. 7-12, 2006. 
[3] E. Ekaette, R.C. Lee, D.L. Cooke, S. Iftody, and P. Craighead, "Probabilistic fault tree analysis of a radiation treatment system risk analysis," An International Journal, vol. 27, pp. 1395-1410, 2007.

[4] K.H. LeBeau, and S.J. Wadia-Fascetti, "Fault tree analysis of schoharie creek bridge collapse", Journal of Performance of Constructed Facilities, vol. 21, pp. 320-326, 2007.

[5] S. Dunnett and J.D. Andrews, "Analysis methods for fault trees that contain secondary failures", Proceedings of the Institution of Mechanical Engineers -- Part E -- Journal of Process Mechanical Engineering, vol. 218, pp. 93-102, 2004.

[6] RA La Band, and J.D. Andrews, "Phased mission modelling using fault tree analysis", Proceedings of the Institution of Mechanical Engineers -- Part E -- Journal of Process Mechanical Engineering, vol. 218, pp. 83-91, 2004.

[7] N. Beauchamp, B.J. Lence, and C. Bouchard, "Technical hazard identification in water treatment using fault tree analysis", Canadian Journal of Civil Engineering, vol. 37, pp. 897-906, 2010.
[8] G. Gunawardane, "Reliability of the internal service encounter", International Journal of Quality \& Reliability Management," vol. 28, pp.1003-1018, 2011.

[9] R.L. Hensley and J. S. Utley, "Using reliability tools in service operations", International Journal of Quality \& Reliability Management, vol. 28, pp. 587-598, 2011.

[10] R. Tao and C.-M. Tam, "System reliability theory based multipleobjective optimization model for construction projects", Automation in Construction, vol. 31, pp. 54-64, 2012.

[11] R. Tao and C.-M. Tam, "System reliability optimization model for construction projects via system reliability theory", Automation in Construction, vol. 22, pp. 340-347, 2011.

[12] C. Beyea Suzanne, "High reliability theory and highly reliable organizations," AORN journal, vol. 81, pp.1319-22, 2005.

[13] Y. Yuanfan, "The study on mechanical reliability design method and its application," Energy Procedia, vol. 17, pp. 467-472, 2012

[14] Adrian Stere PARIS, "Models in mechanical reliability data," Revista Fiabilitate si Durabilitate, vol. 1, pp. 81, 2010.

Received: November 11, 2013

Revised: February 11, 2014

Accepted: March 3, 2014

(C) Yu et al.; Licensee Bentham Open.

This is an open access article licensed under the terms of the Creative Commons Attribution Non-Commercial License (http://creativecommons.org/licenses/ by-nc/3.0/) which permits unrestricted, non-commercial use, distribution and reproduction in any medium, provided the work is properly cited. 